\title{
Comparison Between Stereotactic and Conventional Radiotherapy for Solitary Lung Tumor After Resection of Lung Cancer
}

\author{
SHIGEO TAKAHASHI ${ }^{1}$, TETSUHIKO GO ${ }^{2}$, MASAHIDE ANADA ${ }^{1}$, TOSHIFUMI KINOSHITA ${ }^{1}$, \\ TAKAMASA NISHIDE ${ }^{1}$, HIROYASU YOKOMISE $^{2}$ and TORU SHIBATA ${ }^{1}$ \\ ${ }^{1}$ Department of Radiation Oncology, Kagawa University Hospital, Kagawa, Japan; \\ ${ }^{2}$ Department of General Thoracic, Breast and Endocrine Surgery, \\ Faculty of Medicine, Kagawa University, Kagawa, Japan
}

\begin{abstract}
Background/Aim: We retrospectively compared stereotactic body radiotherapy (SBRT) with conventionally fractionated radiotherapy (CFRT) for a solitary lung tumor after resection of a non-small cell lung cancer (NSCLC), due to a lack of data concerning whether SBRT or CFRT is more effective in this setting. Patients and Methods: SBRT using 48 Gy in 4 fractions was administered to 15 patients with a peripheral tumor (SBRT group). CFRT using 66-70 Gy in 33-35 fractions was administered to 11 patients with a central tumor (CFRT group). Results: The median follow-up time was 32 months (range: 9-79 months). The 3-year overall survival rates in SBRT and CFRT groups were $81 \%$ and $40 \%$, respectively $(p=0.008)$. The 3-year local control rates in SBRT and CFRT groups were $83 \%$ and $35 \%$, respectively $(p=0.035)$. Regarding toxicities, no significant differences were found between the two groups. Conclusion: Compared to CFRT, SBRT may be more effective in solitary-lung-tumor patients after the complete resection of an NSCLC as with inoperable-stage I-NSCLC patients.
\end{abstract}

For patients with an inoperable stage I non-small cell lung cancer (NSCLC), a meta-analysis (1) and randomized controlled trial (2) have shown that stereotactic body radiotherapy (SBRT) has been more effective than conventionally fractionated radiotherapy (CFRT). For patients with a centrally located NSCLC near the pulmonary hilum or the mediastinum, severe

This article is freely accessible online.

Correspondence to: Shigeo Takahashi, Department of Radiation Oncology, Kagawa University Hospital, 1750-1 Ikenobe, Miki-cho, Kita-gun, Kagawa 761-0793, Japan. Tel: +81 878985111, Fax: +81 878912427,e-mail: shigeot@med.kagawa-u.ac.jp

Key Words: Stereotactic ablative radiotherapy, salvage radiotherapy, recurrent lung cancer, second primary lung cancer. toxicities have been reported following SBRT, and clinical trials have been under way with the aim of identifying the optimal SBRT doses (3). For patients with a solitary lung tumor following complete resection of an NSCLC, RT can be performed when the patients are medically inoperable or refuse to undergo surgery. Until the 2000s, CFRT was performed for such patients, and the 2-year overall survival (OS) rate ranged from $30-73 \%$ (4-7). Currently, SBRT is performed for these patients as well. The 2-year OS rate of $61-91 \%$ following SBRT (8-12) seems more favorable compared to CFRT. However, there is a lack of data as to whether SBRT or CFRT is more effective in this setting. Therefore, we retrospectively compared SBRT with CFRT for patients with a solitary lung tumor following the complete resection of an NSCLC with regard to their efficacy and toxicity.

\section{Patients and Methods}

Eligibility criteria. This retrospective analysis was approved by our institutional review board with approval number H28-111. Patients were considered eligible for this study on the basis of the following criteria: i) patients had a solitary lung tumor that was a postoperative local recurrence (PLR), pulmonary metastasis (PM), or multiple primary lung cancer (MPLC) following the complete resection of an NSCLC; ii) RT alone was performed for the solitary lung tumor between 2006 and 2015 in our institution; and iii) none of the patients had regional or extra-pulmonary distant metastasis at the time of RT. Patients treated with concurrent chemoradiotherapy were excluded.

Subgroup criteria of PLR, PM, or MPLC. PLR was defined as a lesion adjacent to a staple line or a bronchial stump following the complete resection of an NSCLC. As for the lesions excluding PLR, PM and MPLC were differentiated, according to the criteria by Martini et al. (13). The criteria for MPLC are as follows: I) different histology between an MPLC and a completely resected NSCLC or II) same histology between an MPLC and a completely resected NSCLC, with i) more than 2 years tumor-free interval, ii) within 2 years of a tumor-free interval in a different lobe or lung, or iii) with origin from carcinoma in situ. 
Table I. Patient and tumor characteristics.

\begin{tabular}{|c|c|c|c|c|c|c|}
\hline Characteristics at complete resection & Number & $\%$ & $\begin{array}{l}\text { Characteristics at RT for } \\
\text { a solitary lung tumor** }\end{array}$ & Number & $\%$ & $\begin{array}{l}\text { Median } \\
\text { (Range) }\end{array}$ \\
\hline Gender & & & Age (years) & & & $79(61-88)$ \\
\hline Male & 23 & 89 & ECOG-PS & & & \\
\hline Female & 3 & 11 & 0 & 14 & 54 & \\
\hline Histology & & & 1 & 9 & 35 & \\
\hline Adenocarcinoma & 14 & 54 & 2 & 3 & 11 & \\
\hline Squamous cell carcinoma & 8 & 30 & History of COPD & & & \\
\hline Large cell carcinoma & 2 & 8 & Yes & 6 & 23 & \\
\hline Pleomorphic carcinoma & 2 & 8 & No & 20 & 77 & \\
\hline Surgery & & & Histology & & & \\
\hline Pneumonectomy & 2 & 8 & Adenocarcinoma & 1 & 4 & \\
\hline Bilobectomy & 1 & 4 & Squamous cell carcinoma & 3 & 11 & \\
\hline Lobectomy & 14 & 54 & Unknown & 22 & 85 & \\
\hline Segmentectomy & 4 & 15 & Subtype of solitary lung tumor*** & & & \\
\hline Wedge resection & 5 & 19 & PLR & 13 & 50 & \\
\hline VATS & & & $\mathrm{PM}$ & 2 & 8 & \\
\hline Yes & 12 & 46 & MPLC & 11 & 42 & \\
\hline No & 14 & 54 & Maximum diameter of solitary lung tumor (mm) & & & $15(6-30)$ \\
\hline pStage* & & & Operability & & & \\
\hline IA & 11 & 42 & Medically operable with patient refusal & 4 & 15 & \\
\hline IB & 6 & 23 & Medically inoperable & 22 & 85 & \\
\hline IIA & 2 & 8 & Time from surgery (months) & & & $22(0-288)$ \\
\hline IIB & 1 & 4 & RT methods for solitary lung tumor & & & \\
\hline IIIA & 5 & 19 & SBRT & 15 & 58 & \\
\hline Unknown & 1 & 4 & CFRT & 11 & 42 & \\
\hline Adjuvant chemotherapy after surgery & & & Adjuvant chemotherapy after RT & & & \\
\hline Yes & 9 & 35 & Yes & 1 & 4 & \\
\hline No & 17 & 65 & No & 25 & 96 & \\
\hline
\end{tabular}

*Seventh edition of the Union for International Cancer Control; **None of the patients had regional or extra-pulmonary distant metastasis; $* * *$ PLR was defined as a lesion adjacent to a staple line, to a bronchial stump, or in the residual lobe after complete resection of NSCLC. VATS: Videoassisted thoracoscopic surgery; RT: radiotherapy; ECOG-PS: Eastern Cooperative Oncology Group Performance Status; COPD: chronic obstructive pulmonary disease; PLR: postoperative local recurrence; PM: pulmonary metastasis; MPLC: multiple primary lung cancer; SBRT: stereotactic body radiotherapy; CFRT: conventionally fractionated radiotherapy.

Treatment. A vacuum cushion was used to fix the body of the patients who were treated with SBRT. The planning computed tomography (CT) scan under free-breathing was performed using a long-time scan ( 3 seconds/scan) to calculate internal target volume (ITV). CT volume data were then transferred to a 3-dimensional radiation treatment planning system. A physician delineated the target volume on the planning CT. Spicula formation and pleural indentation were included within the ITV. Planning target volume (PTV) margin from the ITV was $5-15 \mathrm{~mm}$ at the physicians' discretion with reference to the respiratory motion estimated via the use of an X-ray simulator.

Eight ports including 4 coplanar and 4 noncoplanar beams were used for SBRT. Three or 4 coplanar beams were used for CFRT. A heterogeneous dose calculation algorithm was used. RT was delivered using 4 or $10 \mathrm{MV}$ and $6 \mathrm{MV}$ photon of a linear accelerator until June 2008 and from July 2008, respectively.

SBRT using 48 Gy in 4 fractions over 1-2 weeks at the isocenter was administered to the patients with a peripheral solitary lung tumor (SBRT group). CFRT using 66-70 Gy in 33-35 fractions over 6.6-7 weeks at the isocenter was administered to the patients with a central solitary lung tumor adjacent to the pulmonary hilum or the mediastinum, to avoid a risk of severe hilar or mediastinal toxicity with SBRT (CFRT group).
Follow-up. Patients were followed up 1 and 3 months following the completion of RT. Subsequently, patients were observed every 3 months. During each follow-up visit a chest X-ray was performed. CT or fluorodeoxyglucose (FDG) positron emission tomography (PET)/CT was performed every 6-12 months to evaluate recurrence. Tumor markers were assessed at the physicians' discretion.

Local recurrence was defined as tumor progression or relapse in the irradiated field. Recurrence which occurred within the lung but appeared outside the post-irradiated change was scored as distant recurrence within the lung. Regional recurrence was defined as the regional lymph node recurrence. Any other recurrence was defined as distant recurrence.

Statistics. OS was defined as the time from the completion of RT to death due to any cause. Local control (LC) was defined as the time from the completion of RT to local recurrence. The Kaplan-Meier method was used to calculate the OS and LC rates. Regarding the OS and LC rates, the log-rank test was used in the analysis. Common Terminology Criteria for Adverse Events, version 4.0 (14), were used to assess the toxicities. Fisher's exact test was used in the analysis of the patient and tumor characteristics and toxicities. A $p$-value of $<0.05$ was considered to indicate statistical 
significance. Statistical analyses were performed using the JMP software, version 11 (SAS Institute, Cary, USA).

\section{Results}

Patient and tumor characteristics. In total, 26 patients were analyzed: 15 and 11 patients in SBRT and CFRT groups, respectively. Patient and tumor characteristics are listed in Table I. Comparison of the patient and tumor characteristics between SBRT and CFRT groups are listed in Table II. A history of adjuvant chemotherapy following surgery was significantly more often performed in the SBRT group compared to the CFRT group ( $p=0.036)$, but the history was not a significant factor for OS and LC rates following RT ( $p=0.232$ and $p=0.547$, respectively). No other characteristics of the patients differed significantly between the SBRT and CFRT groups.

Survival and efficacy. In total, the median follow-up time was 32 months (range:9-79 months): i) SBRT group, 35 months (9-79 months), and ii) CFRT group, 18 months (946 months). The 3-year OS rate in the SBRT and CFRT groups (Figure 1) were $81 \%$ and $40 \%$, respectively $(p=0.008)$. Causes of death were as follows: SBRT group, lung cancer in $3(20 \%)$ and other diseases in $2(13 \%)$ patients; CFRT group, lung cancer in $5(45 \%)$ and other diseases in $2(18 \%)$ patients.

The 3-year LC rate in the SBRT and CFRT groups (Figure $2)$ were $83 \%$ and $35 \%$, respectively $(p=0.035)$. Sites of initial recurrence were as follows: SBRT group, local-only in $1(7 \%)$, local with distant to the adrenal gland in $1(7 \%)$, and distant-only within the lung in $4(27 \%)$ patients; CFRT group, local-only in $5(45 \%)$ and distant-only within the lung in $1(9 \%)$ patient. In the initial recurrence, regional lymph node recurrence did not occur.

Toxicities. Toxicities following RT are listed in Table III. Of the 15 patients treated with SBRT, grade-3 dyspnea occurred in 2 patients $(13 \%)$ who had a history of pneumonectomy or chronic obstructive pulmonary disease, despite their slight radiological changes following SBRT. No other grade-3 or higher toxicities were observed in the SBRT and CFRT groups.

Comparison of the toxicities following RT between the SBRT and CFRT groups are listed in Table IV. No significant differences in the occurrence of grade- 2 radiation pneumonitis and grade 2-3 dyspnea were found between the SBRT and CFRT groups ( $p=1.000$ for both).

\section{Discussion}

To the best of our knowledge, this is the first study to compare SBRT to CFRT for patients with a solitary lung tumor following the complete resection of an NSCLC. These showed
Table II. Comparison of the patient and tumor characteristics between SBRT and CFRT groups.

\begin{tabular}{|c|c|c|c|}
\hline $\begin{array}{l}\text { Characteristics at } \\
\text { complete resection }\end{array}$ & $\begin{array}{l}\text { SBRT group } \\
\quad(\mathrm{n}=15)\end{array}$ & $\begin{array}{l}\text { CFRT group } \\
\quad(\mathrm{n}=11)\end{array}$ & $p$-Value \\
\hline \multicolumn{4}{|l|}{ Histology } \\
\hline Adenocarcinoma & $9(60 \%)$ & $5(45 \%)$ & \multirow[t]{2}{*}{0.692} \\
\hline Others & $6(40 \%)$ & $6(55 \%)$ & \\
\hline \multicolumn{4}{|l|}{ Surgery } \\
\hline$\geq$ Lobectomy & $10(67 \%)$ & $7(64 \%)$ & \multirow[t]{2}{*}{1.000} \\
\hline$\leq$ Segmentectomy & $5(33 \%)$ & $4(36 \%)$ & \\
\hline \multicolumn{4}{|l|}{ VATS } \\
\hline Yes & $7(47 \%)$ & $5(45 \%)$ & \multirow[t]{2}{*}{1.000} \\
\hline No & $8(53 \%)$ & $6(55 \%)$ & \\
\hline \multicolumn{4}{|l|}{ pStage } \\
\hline$\geq$ IIA & $5(33 \%)$ & $3(27 \%)$ & \multirow[t]{2}{*}{1.000} \\
\hline$\leq \mathrm{IB}$ & $10(67 \%)$ & $7(64 \%)^{*}$ & \\
\hline \multicolumn{4}{|l|}{$\begin{array}{l}\text { Adjuvant chemotherapy } \\
\text { after surgery }\end{array}$} \\
\hline Yes & $8(53 \%)$ & $1(9 \%)$ & \multirow[t]{2}{*}{0.036} \\
\hline No & $7(47 \%)$ & $10(91 \%)$ & \\
\hline $\begin{array}{l}\text { Characteristics at RT for } \\
\text { solitary lung tumor }\end{array}$ & $\begin{array}{l}\text { SBRT group } \\
\quad(\mathrm{n}=15)\end{array}$ & $\begin{array}{l}\text { CFRT group } \\
(\mathrm{n}=11)\end{array}$ & $p$-Value \\
\hline \multicolumn{4}{|l|}{ Age (years) } \\
\hline$\geq 80$ & $7(47 \%)$ & $3(27 \%)$ & \multirow[t]{2}{*}{0.428} \\
\hline$<80$ & $8(53 \%)$ & $8(73 \%)$ & \\
\hline \multicolumn{4}{|l|}{ ECOG-PS } \\
\hline 0 & $8(53 \%)$ & $6(55 \%)$ & \multirow[t]{2}{*}{1.000} \\
\hline 1 or 2 & $7(47 \%)$ & $5(45 \%)$ & \\
\hline \multicolumn{4}{|l|}{ History of COPD } \\
\hline Yes & $3(20 \%)$ & $3(27 \%)$ & \multirow[t]{2}{*}{1.000} \\
\hline No & $12(80 \%)$ & $8(73 \%)$ & \\
\hline \multicolumn{4}{|l|}{ PLR } \\
\hline Yes & $6(40 \%)$ & $7(64 \%)$ & \multirow[t]{2}{*}{0.428} \\
\hline No & $9(60 \%)$ & $4(36 \%)$ & \\
\hline \multicolumn{4}{|l|}{ PM } \\
\hline Yes & $2(13 \%)$ & $0(0 \%)$ & \multirow[t]{2}{*}{0.492} \\
\hline No & $13(87 \%)$ & $11(100 \%)$ & \\
\hline \multicolumn{4}{|l|}{ MPLC } \\
\hline Yes & $7(47 \%)$ & $4(36 \%)$ & \multirow[t]{2}{*}{0.701} \\
\hline No & $8(53 \%)$ & $7(64 \%)$ & \\
\hline \multirow{2}{*}{\multicolumn{4}{|c|}{$\begin{array}{l}\text { Maximum diameter of solitary } \\
\text { lung tumor }(\mathrm{mm})\end{array}$}} \\
\hline & & & \\
\hline$>20$ & $2(13 \%)$ & $4(36 \%)$ & \multirow[t]{2}{*}{0.348} \\
\hline$\leq 20$ & $13(87 \%)$ & $7(64 \%)$ & \\
\hline \multicolumn{4}{|l|}{ Time from surgery (months) } \\
\hline$\geq 24$ & $6(40 \%)$ & $4(36 \%)$ & 1.000 \\
\hline$<24$ & $9(60 \%)$ & $7(64 \%)$ & \\
\hline $\begin{array}{l}\text { Adjuvant chemotherapy } \\
\text { after RT }\end{array}$ & & & \\
\hline Yes & $0(0 \%)$ & $1(9 \%)$ & 0.423 \\
\hline No & $15(100 \%)$ & $10(91 \%)$ & \\
\hline
\end{tabular}

*One patient with unknown characteristics in the CFRT group was excluded in this row. SBRT: Stereotactic body radiotherapy; CFRT: conventionally fractionated radiotherapy; VATS: video-assisted thoracoscopic surgery; RT: radiotherapy; ECOG-PS: Eastern Cooperative Oncology Group Performance Status; COPD: chronic obstructive pulmonary disease; PLR: postoperative local recurrence; PM: pulmonary metastasis; MPLC: multiple primary lung cancer. 


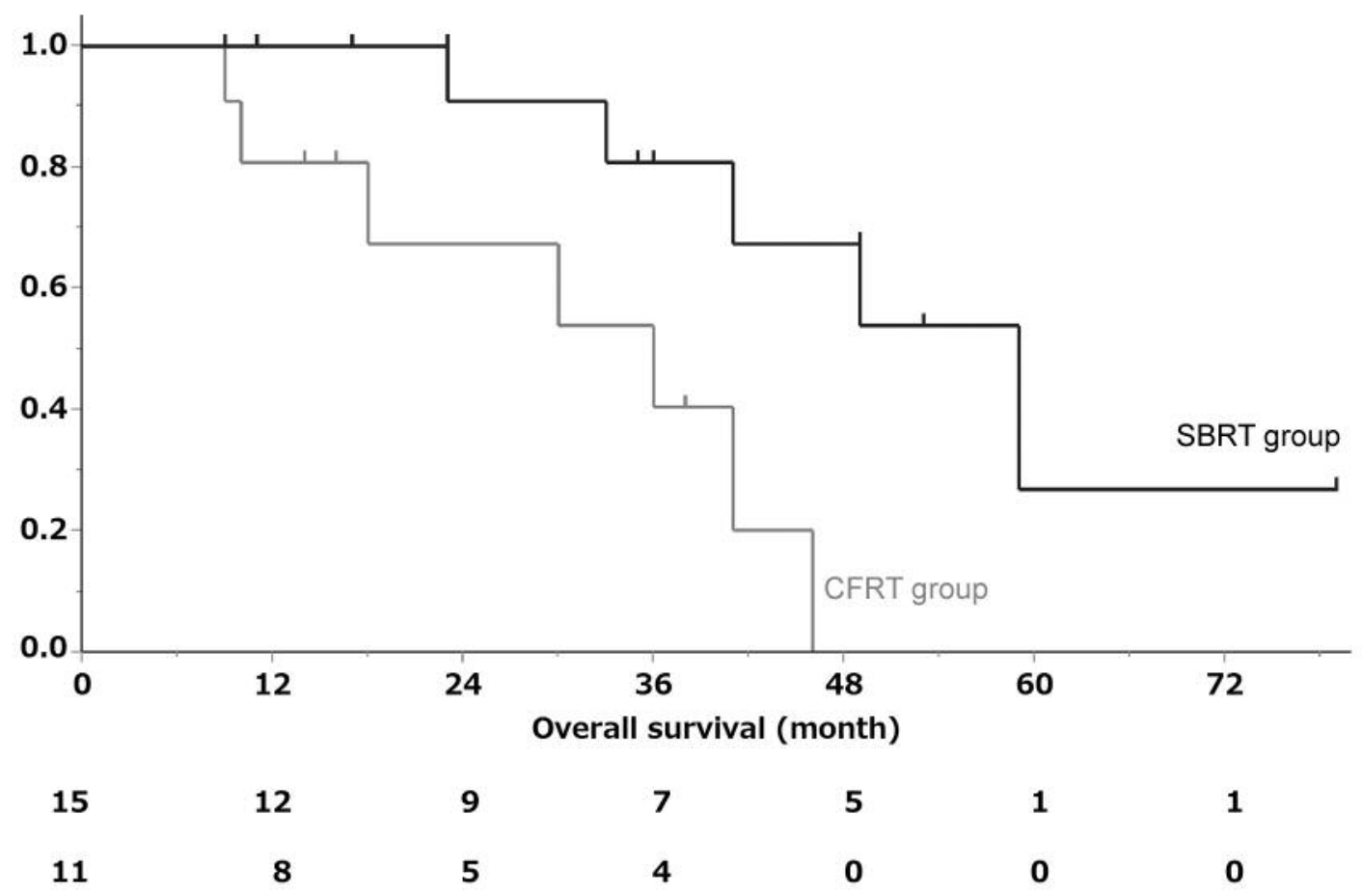

Figure 1. The 3-year overall survival rates in the stereotactic body radiotherapy (SBRT) and conventionally fractionated radiotherapy (CFRT) groups were $81 \%$ and $40 \%$, respectively $(p=0.008)$.

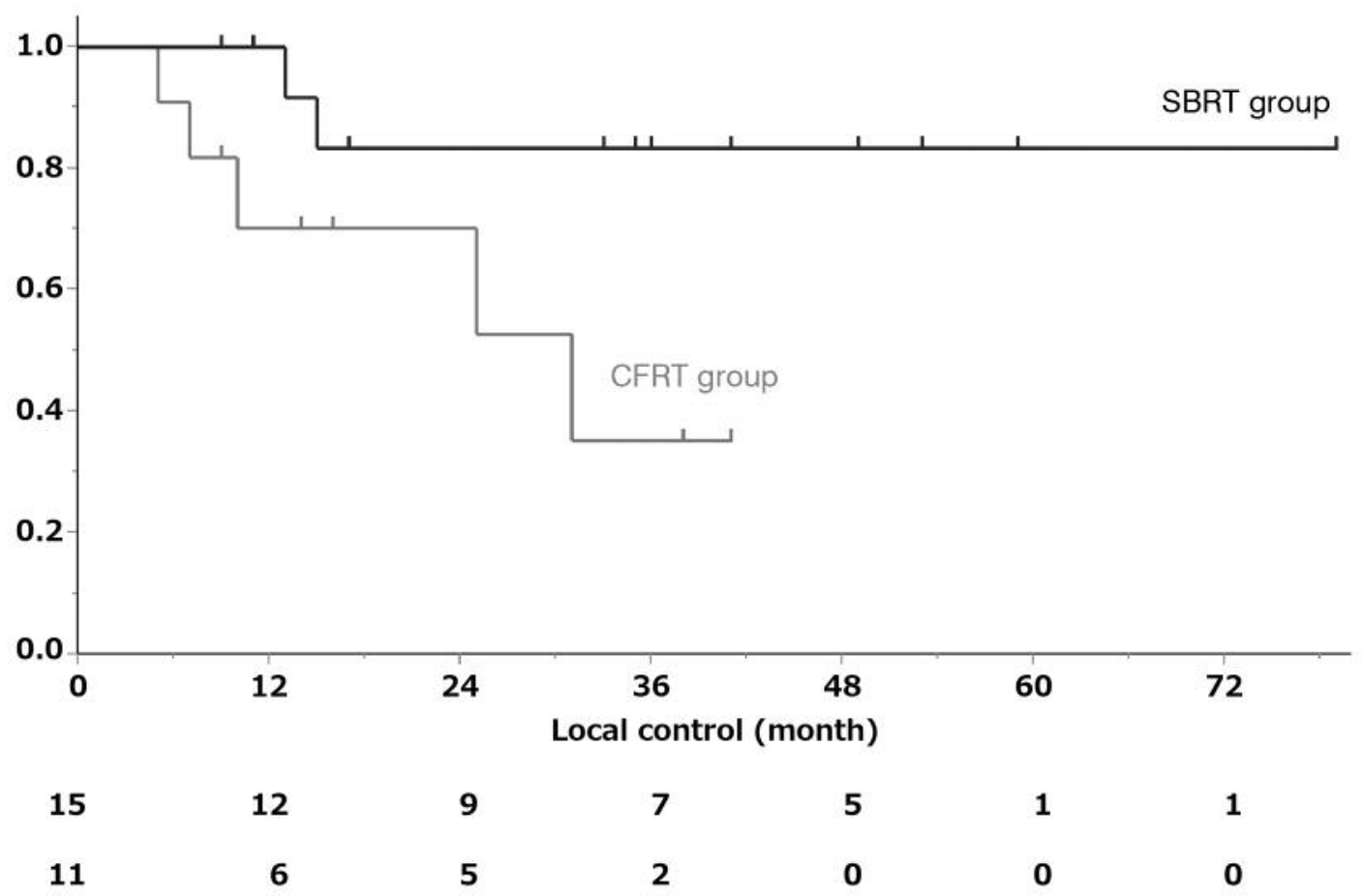

Figure 2. The 3-year local control rates in the stereotactic body radiotherapy (SBRT) and conventionally fractionated radiotherapy (CFRT) groups were $83 \%$ and $35 \%$, respectively $(p=0.035)$. 
Table III. Toxicities following RT

\begin{tabular}{lrrr}
\hline & Grade & Number & $\%$ \\
\hline Radiation pneumonitis & 0 & 3 & 12 \\
& 1 & 19 & 73 \\
& 2 & 4 & 15 \\
& 3 & 0 & 0 \\
Dyspnea & 4 & 0 & 0 \\
& 5 & 0 & 0 \\
& 0 & 12 & 46 \\
Chest pain & 1 & 8 & 31 \\
& 2 & 4 & 15 \\
& 3 & 2 & 8 \\
Radiation esophagitis & 4 & 0 & 0 \\
& 5 & 0 & 0 \\
& 0 & 23 & 88 \\
& 1 & 3 & 12 \\
& 2 & 0 & 0 \\
& 3 & 0 & 0 \\
& 4 & 0 & 0 \\
& 5 & 0 & 0 \\
& 0 & 22 & 84 \\
& 1 & 2 & 8 \\
& 2 & 2 & 8 \\
& 3 & 0 & 0 \\
& 4 & 0 & 0 \\
& 5 & 0 & 0 \\
\hline
\end{tabular}

RT: Radiotherapy.

a significantly better OS with SBRT compared to CFRT, similar to patients with an inoperable stage I NSCLC (1).

Following CFRT the reported rates of the 2-year OS and grade 3 toxicity or higher have been shown to be in the range: $30-73 \%$ and $0 \%$, respectively (4-7) and following SBRT $61-91 \%$ and $2-15 \%$, respectively (8-12). We consider our results to be comparable to the published results.

Regarding toxicities, a retrospective study of patients with or without a history of lung resection has shown that grade 2 pulmonary toxicity or higher following SBRT tended to increase in patients with previous lung resection compared to others, although there was no trend for grade 2 radiationinduced pneumonitis or higher (12). In our study, grade 3 dyspnea occurred in 2 patients, despite their slight radiological changes following SBRT. Therefore, we should probably pay attention to pulmonary toxicities even if there were only slight radiological changes following SBRT in patients with a history of lung resection.

A solitary lung tumor following the complete resection of an NSCLC could be classified as a PLR, PM, or MPLC. Post CFRT data have been limited to PLR and are missing for PM or MPLC (4-7). On the other hand, post SBRT data have been published for all subgroups. With regards to PLR, the 2 -year OS has been shown to be $76 \%$ following SBRT (9). Between PM and MPLC, no significant difference in OS
Table IV. Comparison of toxicity between SBRT and CFRT groups following $R T^{*}$.

\begin{tabular}{lccc}
\hline & $\begin{array}{c}\text { SBRT group } \\
(\mathrm{n}=15)\end{array}$ & $\begin{array}{c}\text { CFRT group } \\
(\mathrm{n}=11)\end{array}$ & $p$-Value \\
\hline $\begin{array}{l}\text { Radiation pneumonitis } \\
\text { Grade 0-1 }\end{array}$ & $13(87 \%)$ & $9(82 \%)$ & 1.000 \\
$\quad$ Grade 2 & $2(13 \%)$ & $2(18 \%)$ & \\
Dyspnea & & & \\
$\quad$ Grade 0-1 & $12(80 \%)$ & $8(73 \%)$ & 1.000 \\
Grade 2-3 & $3(20 \%)$ & $3(27 \%)$ & \\
Chest pain & & & \\
$\quad$ Grade 0 & $14(93 \%)$ & $9(82 \%)$ & 0.556 \\
Grade 1 & $1(7 \%)$ & $2(18 \%)$ & \\
Radiation esophagitis & $15(100 \%)$ & $9(82 \%)$ & 0.169 \\
$\quad \begin{array}{l}\text { Grade 0-1 } \\
\text { Grade 2 }\end{array}$ & $0(0 \%)$ & $2(18 \%)$ & \\
\hline
\end{tabular}

*No other grade 3-5 toxicities were observed. SBRT: Stereotactic body radiotherapy; CFRT: conventionally fractionated radiotherapy; RT: radiotherapy.

following SBRT has been observed; with a 3-year OS at $61 \%$ and $62 \%$, respectively (11). From these data it can be suggested that no marked difference for OS might be among the 3 subgroups following SBRT. In our study, no significant differences of tumor characteristics for PLR, PM and MPLC were observed between the SBRT and CFRT groups. Therefore, the influence of subgroups was probably restrictive in our study.

The histology of the irradiated tumor in our study was unknown in $85 \%$ patients. Because of comorbidities, refusals, tumor location, and other parameters, there have been different degrees of difficulty in obtaining the pathological diagnosis before RT from patients with a solitary lung tumor following the complete resection of an NSCLC. Other studies of SBRT for a solitary lung tumor following complete resection of NSCLC included $49-80 \%$ patients with an unknown histolopathology (8-11). Therefore, we consider our results to be comparable to the published results.

Because of its retrospective nature, this study has certain limitations, such as the single institutional design and the small number of events with unknown long-term results.

In conclusion, SBRT may be more effective compared to CFRT in patients with solitary lung tumors following the complete resection of an NSCLC similar to patients with an inoperable stage I NSCLC.

\section{Conflicts of Interest}

The Authors declare that they have no competing interests in regard to this study. 


\section{Authors' Contributions}

ST and TG coordinated the entire study. Patient clinical data collection were performed by ST, MA, TK, and TN. Data analysis was performed by ST. The article was prepared by ST. Corrections and improvements were suggested by TG, MA, TK, TN, HY, and TS. All authors read and approved the final article.

\section{Acknowledgements}

This study was supported by JSPS KAKENHI (grant number 15K19798).

\section{References}

1 Grutters JP, Kessels AG, Pijls-Johannesma M, De Ruysscher D, Joore MA and Lambin P: Comparison of the effectiveness of radiotherapy with photons, protons and carbon-ions for nonsmall cell lung cancer: a meta-analysis. Radiother Oncol 95(1): 32-40, 2010. PMID: 19733410. DOI: 10.1016/j.radonc. 2009.08.003

2 Ball D, Mai T, Vinod S, Babington S, Ruben J, Kron T, Chesson B, Herschtal A, Vanevski M, Rezo A, Elder C, Skala M, Wirth A, Wheeler G, Lim A, Shaw M, Schofield P, Irving L and Solomon B: Stereotactic ablative radiotherapy versus standard radiotherapy in stage 1 non-small-cell lung cancer (TROG 09.02 CHISEL): a phase 3, open-label, randomised controlled trial. Lancet Oncol 20(4): 494-503, 2019. PMID: 30770291. DOI: 10.1016/S1470-2045(18)30896-9

3 Nagata Y and Kimura T: Stereotactic body radiotherapy (SBRT) for Stage I lung cancer. Jpn J Clin Oncol 48(5): 405-409, 2018. PMID: 29635536. DOI: 10.1093/jjco/hyy034

4 Curran WJ Jr, Herbert SH, Stafford PM, Sandler HM, Rosenthal SA, McKenna WG, Hughes E, Dougherty MJ and Keller S: Should patients with post-resection locoregional recurrence of lung cancer receive aggressive therapy? Int J Radiat Oncol Biol Phys 24(1): 25-30, 1992. PMID: 1324898.

5 Leung J, Ball D, Worotniuk $\mathrm{T}$ and Laidlaw C: Survival following radiotherapy for post-surgical locoregional recurrence of non-small cell lung cancer. Lung Cancer 13(2): 121-127, 1995. PMID: 8581391.

6 Kagami Y, Nishio M, Narimatsu N, Mjoujin M, Sakurai T, Hareyama $M$ and Saito A: Radiotherapy for locoregional recurrent tumors after resection of non-small cell lung cancer. Lung Cancer 20(1): 31-35, 1998. PMID: 9699185.
7 Jeremic B, Shibamoto Y, Milicic B, Milisavljevic S, Nikolic N, Dagovic A, Aleksandrovic J and Radosavljevic-Asic G: External beam radiation therapy alone for loco-regional recurrence of non-small-cell lung cancer after complete resection. Lung Cancer 23(2): 135-142, 1999. PMID: 10217617.

8 Haasbeek CJ, Lagerwaard FJ, de Jaeger K, Slotman BJ and Senan S: Outcomes of stereotactic radiotherapy for a new clinical stage I lung cancer arising postpneumonectomy. Cancer 115(3): 587-594, 2009. PMID: 19130457. DOI: 10.1002/ cncr. 24068

9 Takeda A, Sanuki N, Eriguchi T, Enomoto T, Yokosuka T, Kaneko T, Handa H, Aoki Y, Oku Y and Kunieda E: Salvage stereotactic ablative irradiation for isolated postsurgical local recurrence of lung cancer. Ann Thorac Surg 96(5): 1776-1782, 2013. PMID: 23998410. DOI: 10.1016/j.athoracsur.2013.06.014

10 Thompson R, Giuliani M, Yap ML, Atallah S, Le LW, Sun A, Brade A, Cho BC, Bezjak A and Hope A: Stereotactic body radiotherapy in patients with previous pneumonectomy: safety and efficacy. J Thorac Oncol 9(6): 843-847, 2014. PMID: 24828663. DOI: $10.1097 / \mathrm{JTO} .0000000000000159$

11 Nishiyama K, Kodama K, Teshima T and Tada H: Stereotactic body radiotherapy for second pulmonary nodules after operation for an initial lung cancer. Jpn J Clin Oncol 45(10): 947-952, 2015. PMID: 26238818. DOI: 10.1093/jjco/hyv113

12 Hayes JT, David EA, Qi L, Chen AM and Daly ME: Risk of pneumonitis after stereotactic body radiation therapy in patients with previous anatomic lung resection. Clin Lung Cancer 16(5): 379-384, 2015. PMID: 25737143. DOI: 10.1016/j.cllc.2015. 01.006

13 Martini N and Melamed MR: Multiple primary lung cancers. J Thorac Cardiovasc Surg 70(4): 606-612, 1975. PMID: 170482.

14 Common Terminology Criteria for Adverse Events, version 4.0. Available at https://ctep.cancer.gov/protocolDevelopment/ electronic_applications/docs/CTCAE_4.03.xlsx. Last accessed on 9th May 2019. 